\title{
Impact of Temperature and Relative Humidity on PMD in Directly Buried Optical Fibre Cables in Semi-Arid and Tropical Highlands in Kenya
}

\author{
Moses Ndunda $\mathbb{D}^{1},{ }^{1}$ Alix Dehayem-Kamadjeu, ${ }^{2}$ and David Waswa ${ }^{3}$ \\ ${ }^{1}$ University of Nairobi Kenya, Chiromo Campus, OSA Student Member and Optics Transmission Engineer in Liquid Telecom Kenya, \\ Nairobi, Kenya \\ ${ }^{2}$ Department of Physics and Researcher in Applied Optics Research Group in University of Nairobi, Chiromo Campus, Nairobi, Kenya \\ ${ }^{3}$ Fibre Optics and Laser Research Group in Department of Physics, University of Eldoret, Eldoret, Kenya
}

Correspondence should be addressed to Moses Ndunda; ndundamm@students.uonbi.ac.ke

Received 28 August 2018; Revised 2 November 2018; Accepted 11 November 2018; Published 2 December 2018

Academic Editor: Sulaiman W. Harun

Copyright (C) 2018 Moses Ndunda et al. This is an open access article distributed under the Creative Commons Attribution License, which permits unrestricted use, distribution, and reproduction in any medium, provided the original work is properly cited.

\begin{abstract}
The telecommunication industry has implemented fibre deployment guidelines that reliably safeguard cable health during installation in the field. While installed fibre cables remain buried in the field, temperature and moisture in the locality subject them to mechanical expansions and corrosion. Directly buried fibre cables experience accelerated degradation that results from exposure to harsh environments. This increases pulse spreading and overlaps, with a mean time duration, known as Differential Group Delay (DGD), on the signal, as it propagates along the cable. DGD is stochastic; thus, Mean DGD is determined and presented as Polarization Mode Dispersion (PMD). This work undertook a real life assessment of how fluctuations in temperature and relative humidity influence PMD in directly buried fibre optical links, in a case study that focused on the fibre cable network owned by Liquid Telecom Kenya. The network spans across two key climatic ecosystems, namely, rift valley highlands and northern lowlands. The analysis revealed that fibre cables experience higher PMD in semi-arid areas by a factor of 2.6, compared to highland areas.
\end{abstract}

\section{Introduction}

Fibre cables that are directly buried in the ground often encounter operating conditions that impact negatively their performance, particularly with regard to high capacity data transmission. Temperature and humidity variations in the directly buried cables have been cited as significant influences on Polarization Mode Dispersion (PMD) [1, 2]. This can be very challenging to economies, including Kenya, which operate liberal policies on fibre cable infrastructure. Under such environments, individual fibre cable providers independently deploy and maintain their own infrastructure. Given that fresh excavation of areas where fibre cables are laid is an expensive exercise, it is not economically viable to upgrade the already deployed cables to duct standards. Existing fibre plants therefore require managing until they attain their endlife. This implies that telecommunication providers must keep tracking the PMD fluctuations associated with the cables in the field so as to determine the appropriate period to replace them. This has to be undertaken in a timely manner so as to minimize the traffic disruptions to customers, underpinned by the emerging regard for consumer rights.

The variants can be monitored for their impact on data transmission in the cables. This could be undertaken in different localities where the cables pass, so as to inform associated network designs and engineering. Such monitoring is valuable because the behavior of fibre cables is best analyzed using data that is specific to cables buried in the field at given localities [3]. PMD is nonlinear. It is therefore deterministic or stochastic due to changes in weather, mechanical stress, and/or strain while the cables remain installed in the field [4]. All data transmission designs therefore ought to factor PMD impacts in any fibre cable links. Dead cables point to their inability to transmit data through them without loss of traffic, which calls for their replacement. 


\section{Literature Review}

PMD analyses in different climatic regions have exhibited varied Maxwellian Distribution Functions (PDF). This means that PMD is influenced by the environment and varied for different climatic zones [3]. Environmental changes like temperature and moisture lead to mechanical stain and stress, that in turn influence PMD fluctuations in fibre cables [5]. Since the cables are exposed to strain and stress, they develop cross-sectional deformations in their core cross sections. The cores tend to lose the circular cross section to elliptical or worse that leads to high birefringence and signal mode coupling [6]. Besides the mechanical stress and strain on the cables, temperature and humidity also affect fibre cables.

Distributed Temperature Sensing (DTS) technique for testing the inside of fibre cable cores and use of weather stations to test the outside temperatures in aerial cables have both revealed that either approach is reliable in analyzing the impact of temperature on PMD in fibre cables $[1,2,7]$.

For buried cables, algorithms have been applied on metrological weather data to determine temperature at the depth where the cable is buried [7]. This method has been used to analyze frequency-shifts and chromatic dispersion. Factors like depths where the fibre cable is buried, specific heat capacity, thermal conductivity, and density of the soil have been taken into account by use of an algorithm $[7,8]$.

Analysis of temperature fluctuations inside the cable using DTS and outside the cable using metrological data has been applied alongside various PMD tests techniques. An example is Scrambled State-of-polarization Analysis (SSA) and Generalized InterferomeTrY (GINTY) that have been compared and, with consistency, demonstrated that temperature fluctuations have an impact on PMD [9]. Algorithms [7] have been applied to metrological weather data for buried cables and so far been only applied to chromatic dispersion (CD) analyses, but not on PMD.

PMD analyses based on laboratory simulation where the cable was placed in temperature controlled chambers have also been undertaken [2]. For this, a temperature range was set to an upper and a lower limit; then the variable (temperature) is adjusted in steps, so as to simulate an adiabatic environment. The same setup is repeated, with temperature being randomly varied in order to simulate fluctuations in an isothermal environment $[2,10]$. A simulation in both adiabatic and isothermal ensures that all possible temperature fluctuation patterns experienced in the field are exposed to the fibre cable in the laboratory. Such simulations have also been used alongside PMD tests using Jones Matrix Eigen Analysis (JME) [2,10] and have concurred with the fieldbased methods that temperature has an impact on PMD fluctuations [3].

All tests on temperature vs PMD are normally conducted at uniformly spaced time intervals (typically between 1 hour and 2 hours) to allow distinct transitions in both variables. Various PMD analysis techniques have been conducted using the said intervals and have demonstrated consistent trend showing rise and drop for both PMD and temperature [2, 79]. The trend has been very closely related, which confirms the strong dependence of PMD on temperature.
Studies on the response of PMD to fluctuations caused by relative humidity in telecommunication fibre optics have not attracted much attention. This could partly be attributed to the observation that fluctuations in relative humidity have impact on temperature [11]. Another assumption is that the impact of relative humidity is effectively managed in telecommunication fibre cables by filling the gaps between fibre cores and protective jacket with water-blocking agents [12]. That does not however mean that fibre optical cables are not affected by fluctuations in relative humidity.

Studies that have used the zero-stress aging technique to simulate relative humidity in laboratories have concentrated on the impact of cables' mechanical strength and connections with the rate of aging of the cables $[2,13,14]$. Other studies have focused on using the FOCs high response to relative humidity to produce humidity sensors [15].

Since relative humidity and temperature are inseparable in the field, this study therefore acquired relative humidity data alongside temperature fluctuations in order to examine the nature of their combined contributions to PMD in the field.

\section{Experimental Setup}

The locations for the Fibre under Test (FUT) were identified and selected distinctively to represent lowland and highland climates in Kenya [8] as presented in Figure 1. Analyzed sections for highland climate are labelled in blue while sections for lowlands are labelled in red. The FUT was part of jacketed direct buried cable that was not deployed in ducts and was serving a live network since 2007.

Two locations selected for tests were as follows: a section of about $60 \mathrm{~km}$ in highland area (Mau-Summit) located at coordinates $-0.149087 \mathrm{~N}, 35.687885 \mathrm{E}$ at the highest altitude peak $(2850 \mathrm{~m})$ within cable route and a similar length located in a low altitude area (Sultan-Hamud $(1500 \mathrm{~m})$ ) located at coordinates $-1.906248 \mathrm{~N}, 37.279186 \mathrm{E}$. Selection of the study sites excluded the Kenyan coast because of the region's proximity to the Indian Ocean, which makes it have higher alkalinity that results in higher cable corrosion compared to other regions in Kenya. Even so, the Kenya coastal region is only a small percentage of about $4 \%$ of the whole fibre cable that was to be analyzed in this study. PMD tests were randomly undertaken in 2 other locations so as to verify consistency of the tests.

A capacitive soil sensor ML3 [16, 17] was buried at a depth where the fibre cable under test was located. This was typically between $1 \mathrm{~m}$ and $1.2 \mathrm{~m}$ below earth's surface. Humidity tests sought to establish the effect of a mixture of soil particles, air, and water on the performance of the fibre optic cable. Damp soil is essentially a mixture of soil particles, air, and water. These components together determine the dielectric properties of a given soil, including the refractive index $(\sqrt{\varepsilon})$. The refractive index is evaluated from [17].

$$
\sqrt{\varepsilon}=\alpha_{0}+\alpha_{1} \cdot \theta
$$

where $\sqrt{\varepsilon}=1.0+6.175 V+6.303 V^{2}-73.578 V^{3}+183.44 V^{4}$ $-184.78 \mathrm{~V}^{5}+68.017 \mathrm{~V}^{6}$ and $\mathrm{V}$ represents the sensor output in 


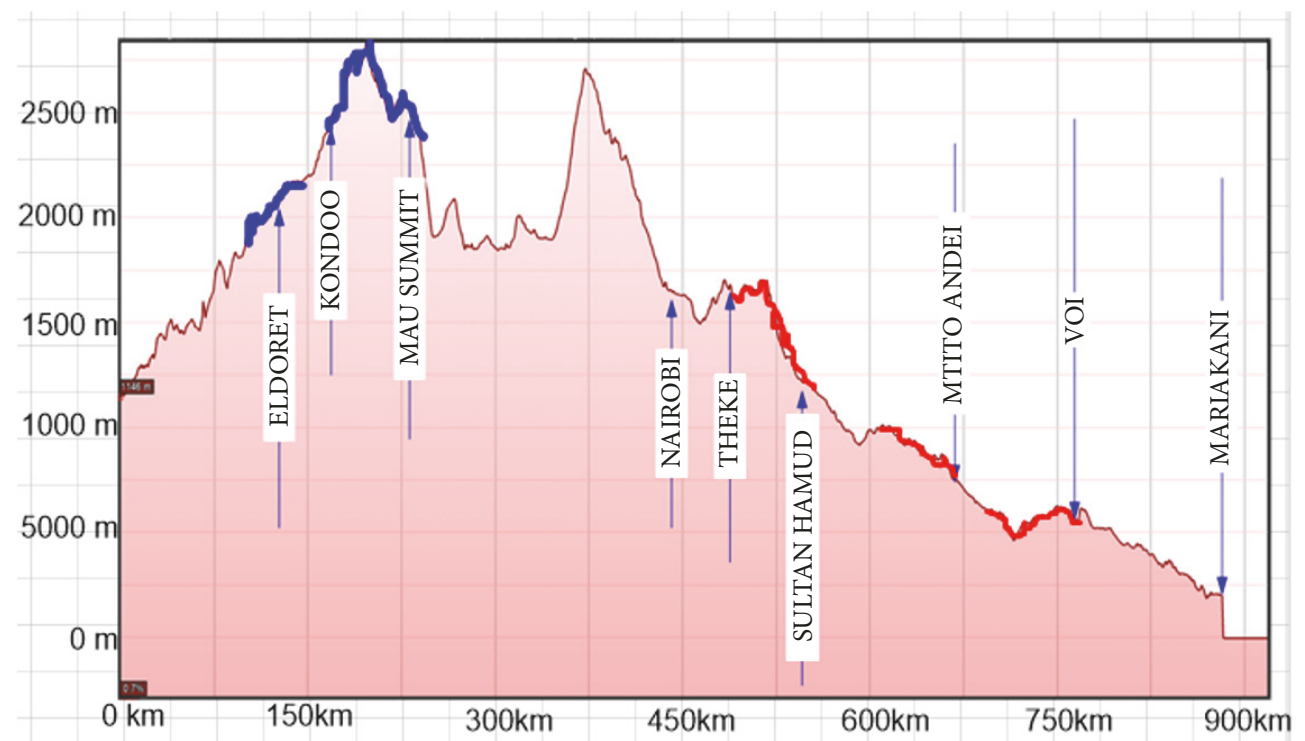

Figure 1: $900 \mathrm{~km}$ cross section from Kenya's sea level (coast) to rift valley highlands through northern lowlands. Vertical plane represents fibre route altitude while horizontal plane represents fibre length.

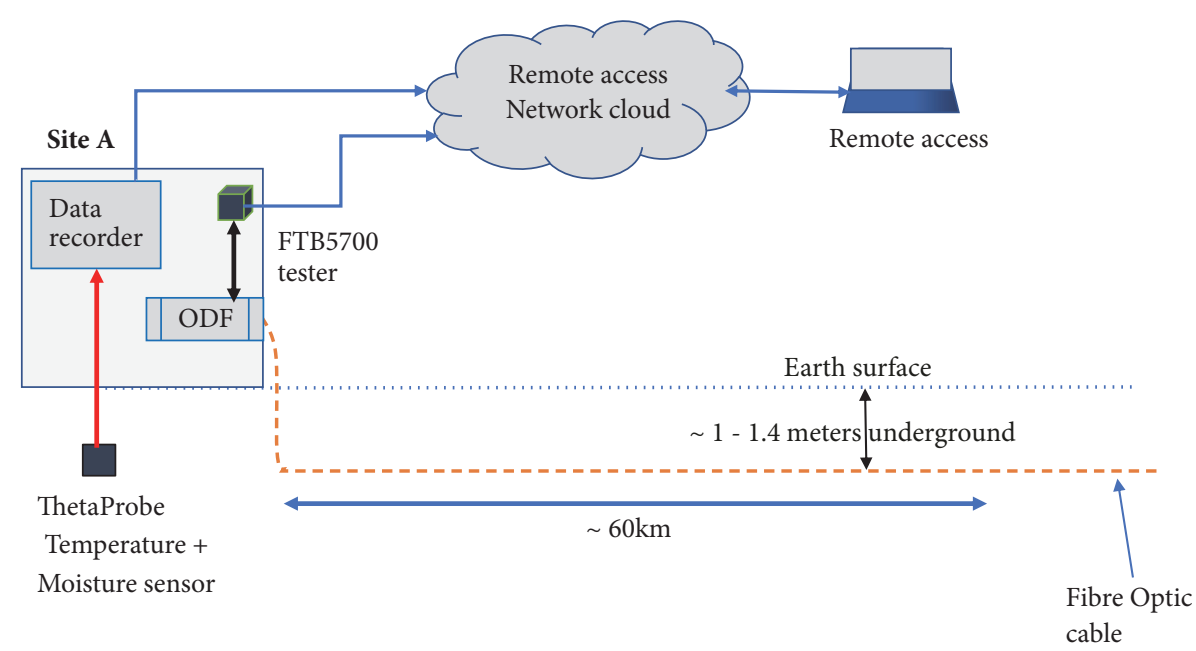

FIGURE 2: Setup of the field tests that were conducted using a single ended tester, moisture, and temperature sensor.

volts. $\alpha_{0}$ and $\alpha_{1}$ are coefficients that conveniently characterize the dielectric properties of a dry and wet soil, respectively. $\theta$ represents moisture.

If $\sqrt{\varepsilon}$ is known, (2) can be rearranged to assist in evaluating the moisture in the soil, as indicated in the equation below [17].

$$
\theta=\frac{\sqrt{\varepsilon}-\alpha_{0}}{\alpha_{1}}
$$

A data logger was configured to query and save sensor readings on an hourly basis, in a bid to register moisture content fluctuations in the entire test period. Deployment of the equipment was undertaken in a manner that ensured that the moisture data relating to different seasons was captured. A ML3 Theta-probe was used to acquire temperaturerelated data. The probe had inbuilt circuitry for measuring temperature alongside soil moisture. The soil temperature was measured using a $10 \mathrm{~K} \Omega$ thermistor, which was mounted on the ML3 and connected to a data logger. The data logger had a look-up chart that contained readings of resistances that corresponded to the temperature of the locality where the thermistor was buried.

Field PMD tests were conducted on the buried fibre cable using the Scrambled State-of-polarization Analysis (SSA) (EXFO FTB-5700) $[18,19]$. Figure 2 is the schematic diagram of the experiment setup in the field. Strands in $60 \mathrm{~km}$ fibre spans were identified in both semi-arid and highland climatic regions. The analyzer is a single ended device so it was placed at one end of the fibre and the other end was spliced to a connector to provide a proper reflection at the end of the $60 \mathrm{kms}$ in a manhole. A mouse bot was then installed in the analyzer to run PMD data acquisition every end of hour. 

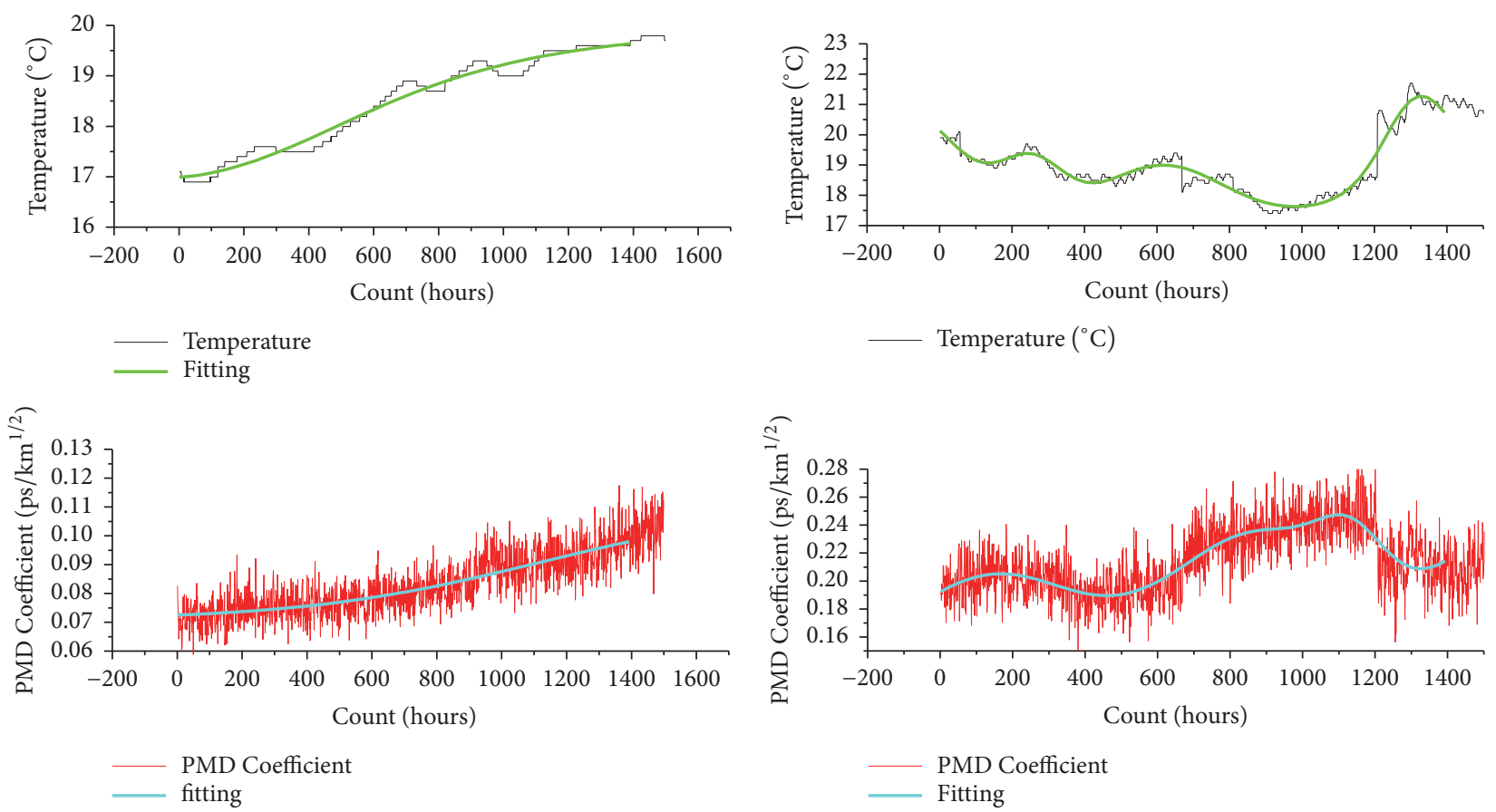

(a)

(b)

Figure 3: (a) Temperature (black) with fitting (green) and PMD (red) with fitting (cyan) for highland climate in Mau-Summit area. (b) Temperature (black) with fitting (green) and PMD trend-line (red) with fitting (cyan) for semi-arid climate in Sultan Hamud area.

Each PMD test-run was configured to coincide with the humidity and temperature data acquisition and ran for the same duration for purposes of correlation. PMD testing in each season also provided the study with the annual fluctuation ranges. PMD values are better expressed in terms of PMD coefficient that is calculated as PMD per square root $\mathrm{km}$ of the fibre length under measurement.

\section{Results and Discussion}

In highland area, highest recorded PMD coefficient was $0.1175 p s \sqrt{k m}$, while the lowest was $0.0588 p s \sqrt{k m}$. A PMD coefficient mean of $0.0836 p s \sqrt{\mathrm{km}}$, a standard deviation of $0.05113 p s \sqrt{\mathrm{km}}$, and a variance of 0.13 were observed. On the other hand, the highest recorded PMD coefficient in semi-arid area was $0.2956 \mathrm{ps} \sqrt{\mathrm{km}}$, and the lowest was 01559 ps $\sqrt{\mathrm{km}}$, while the mean and standard deviation of the PMD were $0.21524 p s \sqrt{\mathrm{km}}$ and $0.02177 p s \sqrt{\mathrm{km}}$, respectively. This effectively led to a variance of 0.1 in semi-arid areas.

The PMD coefficient in semi-arid compared to highland area was high by a factor of 2.6 leading to indications of higher rate of cable PMD aging in semi-arid areas. The various correlations for PMD coefficient alongside temperature and relative humidity in the two climatic zones follow as shown below.

4.1. Temperature Correlation with PMD. In highland area, both temperature and PMD coefficient had an upward trend as seen in Figure 3(a) until test hour 1,500 when both tests ended. Since the cable was buried, the trend in daily temperature fluctuations was stable. This was because the cable did not experience day-night transitions. Clear PMD trends that were in response to distinct temperature transitions can be attributed to general seasonal fluctuations. Change in temperature fluctuations corresponded to changes in PMD values. The correlation demonstrated that changes in temperature had influence on PMD fluctuations, as has also been noted in other studies $[2,7,8,10]$. The graph in Figure 3(a) presents compiled PMD and temperature correlation for highlands (Mau-Summit area)

And the graphs in Figure 3(b) represent temperature and PMD trend-line correlations for semi-arid climate that is located in Sultan Hamud area.

In the semi-arid region, namely, Sultan Hamud, lowest PMD concentrations were between test hours 0 and 500, though the lowest temperature was recorded between test hours 800 and 1000. Highest PMD fluctuations were recorded around test hour 1100 although the period between test hours 1,300 and 1,500 was the hottest, as presented in Figure 3(b).

Temperature fluctuations in the semi-arid area were high compared to those in the highland area. Higher PMD was observed in the semi-arid test area compared to the highland area. It was noted in the period between test counts 450 and 1500 that temperature downward trend corresponded to upward trend in PMD coefficient. The consistency of PMD vs temperature trend-line had an inverse relationship and was a contrast observation compared to temperature vs PMD coefficient relationship in highlands. Given the observations in this analysis and the observations that were made by Haro 

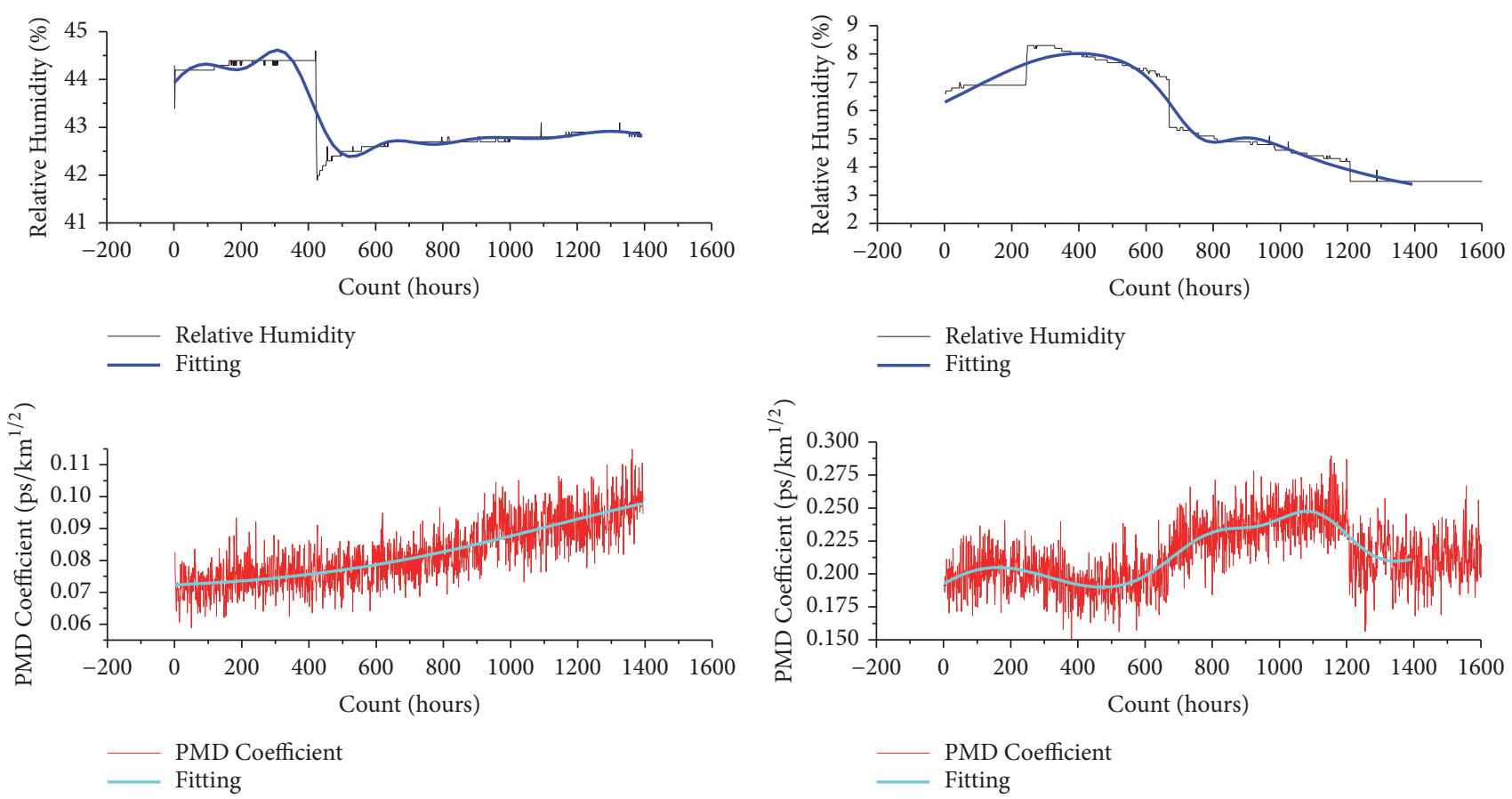

(a)

(b)

Figure 4: (a) Relative humidity (black) with fitting (blue) and PMD coefficient (red) with fitting (cyan) for highland climate in Mau-Summit area. (b) Relative humidity (black) with fitting (blue) and PMD coefficient (red) with fitting (cyan) for semi-arid climate in Sultan Hamud area.

et al., there is an indication that PMD in fibre cables exhibits a clear inverse relationship in environments where temperature exceeds 20 degrees Celsius [20].

4.2. Relative Humidity Correlation with PMD. Relative humidity $(\mathrm{RH})$ in highland area, namely, Mau-Summit, had an average of $42.8 \%$ and a fluctuation range of $2.7 \%$. Relative humidity vs PMD results are presented in Figure 4(a). Major $\mathrm{RH}$ fluctuation incidences were compared with corresponding PMD fluctuations. A key incident was the $2.5 \%$ drop within a duration of 4 hours, which was recorded between test hours 400 and 500. This drop in RH did not trigger a PMD drop but, instead, PMD fluctuations remained uninterrupted. Although RH in highland areas had very minimal fluctuations as seen in Figure 4(a), it was observed that the only notable incidence in the entire 1,600 hours did not have any impact on PMD. This implies that $\mathrm{RH}$ has negligible impact, if any, on PMD in a highland area.

RH in the semi-arid area where the study was undertaken (Sultan Hamud) was very low, compared to that of the highland area (Mau-Summit), but with a higher fluctuation range of 5\%. The fluctuations in semi-arid area were analyzed based on two major incidences: one being a $\mathrm{RH}$ rise incidence and the downward trend, as presented in Figure 4(b).

The first incident was a $1.4 \%$ sharp rise in $\mathrm{RH}$, recorded at test hour 200 and which took 5 hours at the peak, followed by a downward trend until test hour 1,250. During this test period, a direct relationship between $\mathrm{PMD}$ and $\mathrm{RH}$ was observed. This was followed by a stable nonvarying $\mathrm{RH}$ period (second incident) that lasted until test hour 1600 .
During this time, relative humidity remained the same for a period of 400 hours, while the PMD fluctuated with a downward trend and then floored about $100 \mathrm{hrs}$ after $\mathrm{RH}$ floored. A fairly direct relationship between PMD and $\mathrm{RH}$ was observed as seen in Figure 4(b) traces.

$\mathrm{RH}$ did not have impact on PMD in highlands but it was observed that it had a notable influence in semi-arid areas. The reduced influence of PMD in highlands compared to semi-arid environments could be attributed to the small fluctuation in $\mathrm{RH}$ range, of $2.3 \%$ that was recorded, compared to $5 \%$ that was recorded in semi-arid areas. Although the temperature and relative humidity variations do not have wide range of fluctuations, it should be noted that the variations represent real data that was obtained by use of sensors that were buried 1.2 meters underground. The depth is the same that the cable was buried.

\section{Conclusion}

This is the first documented real life study of PMD of fibres deployed in a field, where correlations with $\mathrm{T}$ and $\mathrm{RH} \%$ have been explored. It is noteworthy to stress that the impacts of $\mathrm{RH}$ on PMD cannot be ignored in semi-arid regions, where they correspond to direct relationship for the better part of test durations. Findings of this study further apprise that $\mathrm{RH}$ alone is not sufficient towards investigating the impact caused by fluctuations of temperature and humidity on PMD. This is because, as the results of this study demonstrate, PMD fluctuates in both semi-arid areas and highlands and at times when $\mathrm{RH}$ was stable and nonvarying. In the highlands, 
however, $\mathrm{RH}$ experienced minimal variations that were less likely to lead to meaningful impact on PMD fluctuations.

Findings of this work in the highlands concur with those of other investigations that have been conducted elsewhere on the connection between temperature and PMD fluctuations $[2,3,10]$. The findings of the results in semi-arid area present a unique observation and a contrast for results obtained in other investigations. Variances of 0.1 and 0.13 were observed in respect of the semi-arid and highland areas, respectively. This indicates reduced PMD fluctuation-spread from the mean attributable to semi-arid areas, compared to that for highland areas. It demonstrates reduced PMD fluctuations in buried cables, compared to the 0.42 obtained in laboratory simulations [2] and 0.39 in field tests for those that were conducted in aerial cables in different climatic zones in South Africa [3].

The nature of PMD fluctuations vs temperature and relative humidity in semi-arid area was an interesting finding. This presents a need to further analyze PMD in many other regions that have the same climatic conditions or higher temperature and lower relative humidity to establish the repeatability of outcome of the unique climatic relationship with PMD.

\section{Data Availability}

The field data used to support the findings of this study have been deposited in the figshare repository https://doi.org/ 10.6084/m9.figshare.7333841.v1.

\section{Conflicts of Interest}

The authors declare that they have no conflicts of interest.

\section{Acknowledgments}

We would like to acknowledge our supervisors, Dr. Alix D. Massop and Dr. David W. Waswa, for their invaluable inputs throughout the period of this research. Special thanks are due to Hans Haerdtle, the Chief Technical Officer (C.T.O) of Liquid Telecom East Africa, for giving us an opportunity to analyze Liquid Telecom infrastructure, as well as the facilitation in acquiring test and analysis tools. The entire Liquid Telecom fraternity is also gratefully acknowledged for the support that they individually and collaterally provided us during the study.

\section{References}

[1] J. Bohata, S. Zvanovec, and M. Pisarik, "Outdoor atmospheric influence on polarization mode dispersion in optical cables," pp. 1-4, General Assembly and Scientific Symposium, Beijing, China, 2014.

[2] S. Karlik and G. Yilmaz, Effects Of Temperature On Polarization Mode Dispersion Of G.652 Optical Fibers, Uludag University, Faculty of Engineering and Architecture, Department of Electronics Engineering, Bursa, Turkey, 2006.

[3] T. Gibbon, W. Lorinda, and D. Waswa, "Polarization mode dispersion compensation for the South African optical-fibre telecommunication network," South Afr. J. Sci, vol. 104, pp. 34, 2008.

[4] W. T. Ireeta, V. Musara, and A. Leitch, "Monitoring FOPMD and SO-PMD over time with respect to Environmental conditions," Can. Cent. Sci. Educ, vol. 6, no. 4, pp. 10-15, 2014.

[5] K. R. Lefebvre, "Environmental Effects on Chromatic and Polarization Mode Dispersion," NetTest, 2001.

[6] E. A. Lindholm, H. G. Limberger, M. J. Matthewson et al., "Aging behavior of optical fibers in aqueous environments," in Reliability of Optical Fiber Components, Devices, Systems, and Networks II, 2004.

[7] T. J. Pinkert, O. Böll, L. Willmann et al., "Effect of soil temperature on optical frequency transfer through unidirectional dense-wavelength-division-multiplexing fiber-optic links," Applied Optics, vol. 54, no. 4, pp. 728-738, 2015.

[8] H. C. Ji, J. H. Lee, and Y. C. Chung, "System Outage Probability Due to Dispersion Variation Caused by Seasonal and Regional Temperature Variations," J. Fiber Opt. Commun, vol. 60, no. 2330, pp. 1-3, 2005.

[9] J. Bohata, J. Jaros, S. Pisarik, S. Zvanovec, and M. Komanec, "Long-Term Polarization Mode Dispersion Evolution and Accelerated Aging in Old Optical Cables," IEEE Photonics Technology Letters, vol. 29, no. 6, pp. 519-522, 2017.

[10] P. Kondamuri and C. Allen, PMD Characterization of Installed Fiber, The University of Kansas Center for Research, Lawrence, Kan, USA, 2004.

[11] A. K. Betts, R. Desjardins, D. Worth, and B. Beckage, "Climate coupling between temperature, humidity, precipitation, and cloud cover over the Canadian Prairies," Journal of Geophysical Research: Atmospheres, vol. 119, no. 23, pp. 13305-13326, 2014.

[12] J. Peters, A Comparison of Dry Versus Gel Filled Optical Cables, Sterlight Technologies, 2012.

[13] B. Risch, S. Fox, and R. Delden, Lifetime Prediction of Fiber Optic Cable Materials for Nuclear Power Applications: Evaluation of Failure Mechanism, End of Life Criteria, and Test Methodology, International wire and cable symposium, Rode Island, Pa, USA, 2009.

[14] A. Dwivedi and S. Glaesemann, "Optical Fiber Strength, Fatigue and Handleability After Aging in a Cable," Corning Incorporated, 2011.

[15] M. Batumalay, S. W. Harun, N. Irawati, H. Ahmad, and H. Arof, "A study of relative humidity fiber-optic sensors," IEEE Sensors Journal, vol. 15, no. 3, pp. 1945-1950, 2015.

[16] Delta T devices, ML3 ThetaProbe moisture sensor, Cambridge, 2014.

[17] Delta-T Devices Ltd, User manual for the ML3 ThetaProbe, Delta-T Devices Ltd, 2013.

[18] EXFO Inc, FTB-5700 Single-Ended Dispersion Analyzer, EXFO Inc., 2014.

[19] G. André, C. Hongxin, A. Francis et al., A new test method for the quantitative determination of bad pmd sections along an installed fiber link, EXFO Inc., 2009.

[20] J. Haro and P. R. Horche, "Evolution of PMD with the temperature on installed fiber," Optical Fiber Technology, vol. 14, no. 3, pp. 203-213, 2008. 

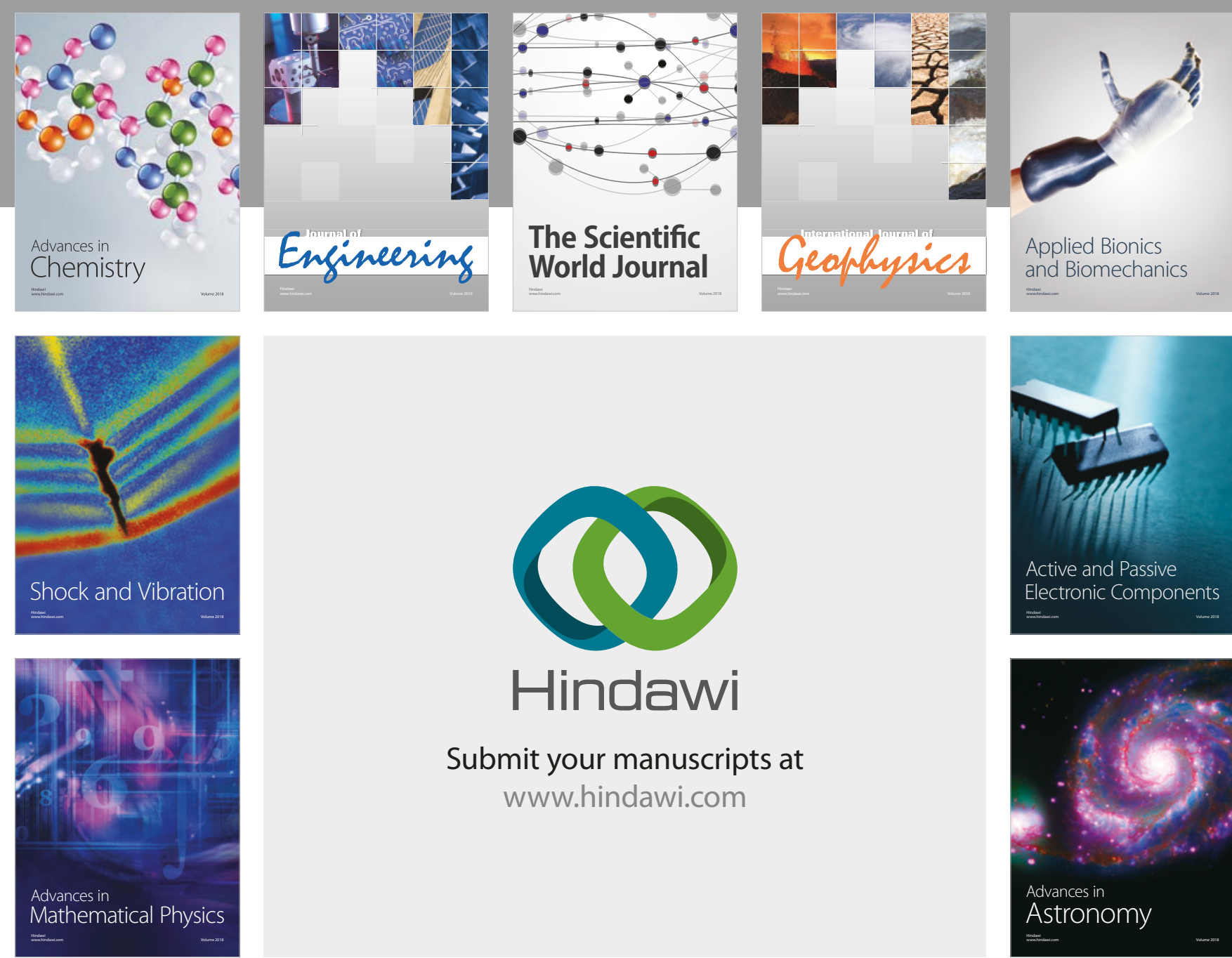

Submit your manuscripts at

www.hindawi.com

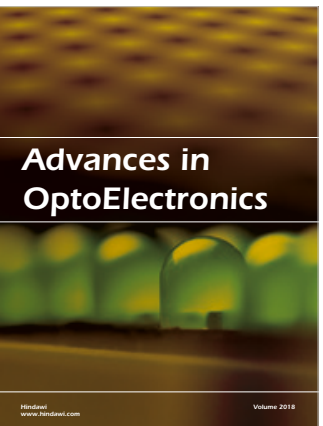

\section{Rotcting Machinery}
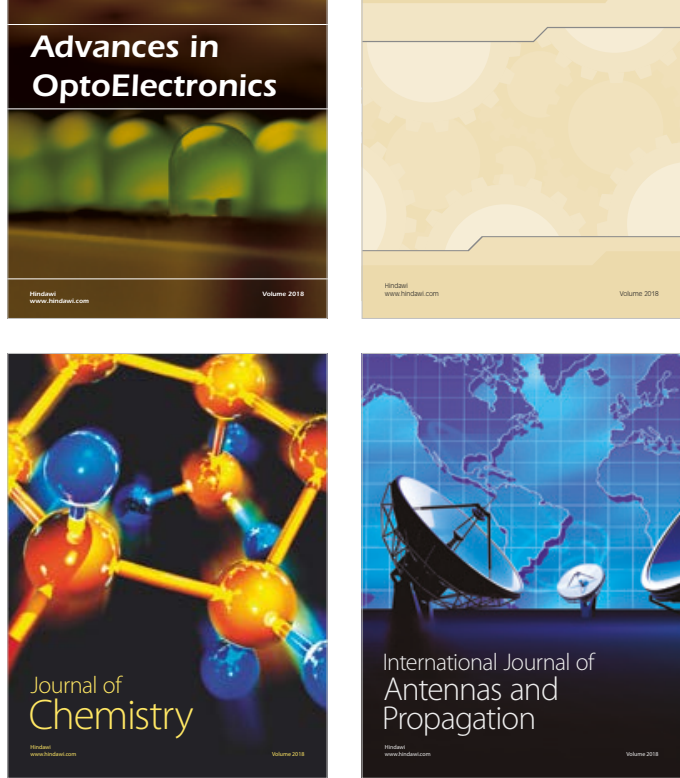

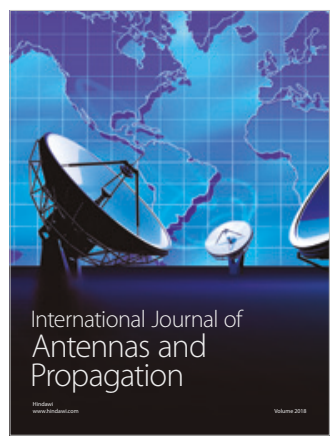

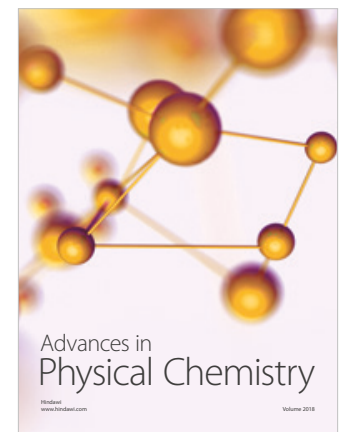

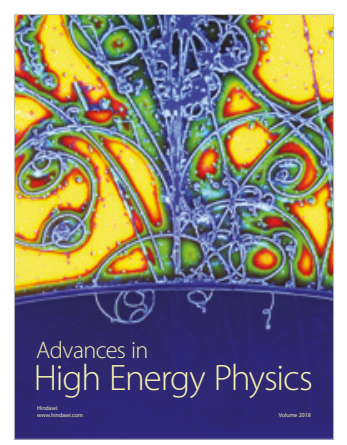

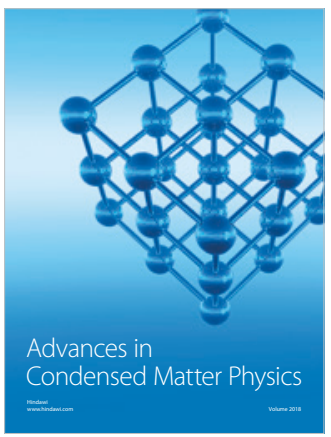

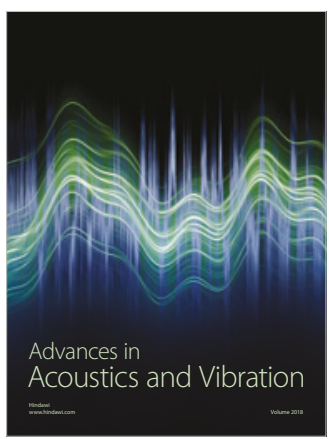

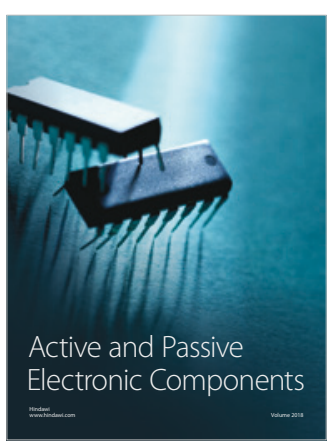
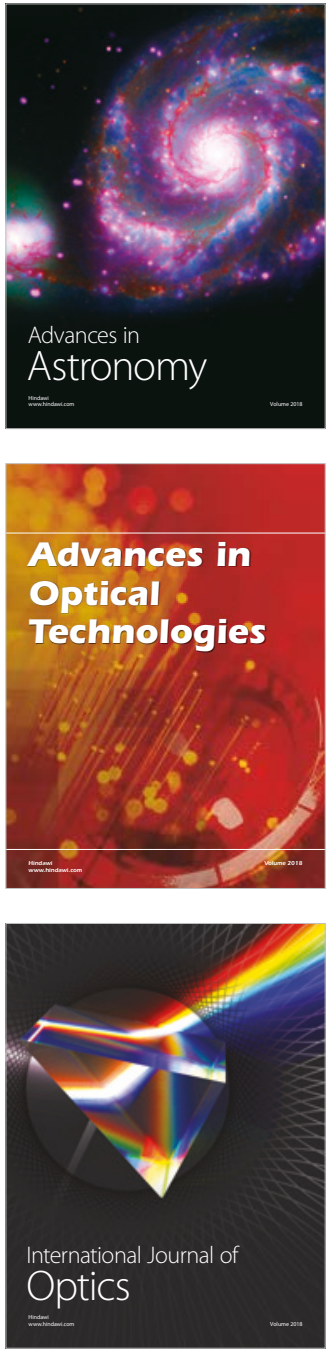